\title{
Post-H1N1 Flu Vaccination Narcolepsy in Switzerland: A Retrospective Survey in the 30 Sleep-Certified Swiss Centers
}

\author{
Ulf Kallweit $^{\mathrm{a}}$ Johannes Mathis ${ }^{\mathrm{a}}$ Oskar G. Jenni ${ }^{\mathrm{b}} \quad$ Raphaël Heinzer $^{\mathrm{d}}$ \\ José Haba-Rubio $^{d}$ Christian R. Baumann ${ }^{c}$ Katerina Cervena ${ }^{e}$ \\ Claudio L.A. Bassetti ${ }^{\mathrm{a}}$ \\ ${ }^{a}$ Department of Neurology, Bern University Hospital, Bern, ${ }^{b}$ Pediatric Sleep Disorders Center, University Children's \\ Hospital Zurich and ${ }^{\mathrm{C} D e p a r t m e n t}$ of Neurology, University Hospital Zurich, Zurich, ${ }^{\mathrm{d}}$ Sleep Center, University \\ Hospital Lausanne, Lausanne, and 'Sleep Laboratory, University Hospitals of Geneva, Geneva, Switzerland
}

\author{
Key Words \\ Post-H1N1 narcolepsy · Narcolepsy · Vaccination · Certified \\ sleep centers $\cdot$ Hypocretin
}

\begin{abstract}
Narcolepsy-cataplexy is a sleep-wake disorder and suggested to be immune-mediated, involving genetic and environmental factors. The autoimmune process eventually leads to a loss of hypocretin neurons in the lateral hypothalamus. Epidemiological studies in several countries proved an increased incidence of narcolepsy after $\mathrm{H} 1 \mathrm{~N} 1$ flu vaccination and infection. This survey in 30 sleep centers in Switzerland led to the identification of $9 \mathrm{H} 1 \mathrm{~N} 1$-vaccinated children and adults as newly diagnosed narcolepsy. Clinical features included the abrupt and severe onset of sleepiness, cataplexy and sleep fragmentation.

๑) 2016 S. Karger AG, Basel
\end{abstract}

\section{Introduction}

Narcolepsy-cataplexy (NC or narcolepsy type 1) is a chronic neurological sleep-wake disorder with a prevalence of 25-50 per 100,000 in western countries [1]. The 'narcoleptic symptom pentad' includes excessive daytime sleepiness (EDS), cataplexy, sleep paralysis, hypnagogic hallucinations and sleep fragmentation. NC is suggested to be an immune-mediated disorder affecting genetically predisposed individuals coupled with exposure to environmental factors. The genetic background is strongly associated with the HLA-DQB ${ }^{*} 06: 02$ genotype [2]. Among environmental factors, bacterial (streptococcus pyogenes) or viral (influenza A H1N1) infections and H1N1 vaccination have been correlated with the onset of NC [3-5]. Ultimately, the suggested autoimmune process degrades hypocretin-producing neurons in the lateral hypothalamus as the main cause of the NC symptoms [6].

Since 2010, several epidemiological observations and studies have pointed to an increased occurrence and risk (3-15 fold) of narcolepsy following H1N1 flu vaccination in autumn 2009 [4, 5, 7-10], as well as after H1N1 disease [11]. The provoking effect of $\mathrm{H} 1 \mathrm{~N} 1$ vaccination was primarily and mainly observed in children, adolescents and young adults $[4,7-10]$.

Different causes for the specific role of Pandemrix ${ }^{\circledR}$ being the pivotal trigger for post $\mathrm{H} 1 \mathrm{~N} 1 \mathrm{NC}$ are discussed (e.g. AS03 adjuvant). Recently, a higher amount of polymeric $\mathrm{H} 1 \mathrm{~N} 1$ virus nucleoprotein probably due to differ-

\section{KARGER}

E-Mail karger@karger.com

www.karger.com/ene (c) 2016 S. Karger AG, Basel

0014-3022/16/0754-0105\$39.50/0
Dr. Ulf Kallweit

Neurology Department

Bern University Hospital, Inselspital

Freiburgstrasse 18, CH-3010 Bern (Switzerland)

E-Mail ulf.kallweit@insel.ch 
Table 1. Clinical, MSLT, PSG and laboratory features of post$\mathrm{H} 1 \mathrm{~N} 1$ flu vaccination $\mathrm{NC}$

\begin{tabular}{|c|c|c|c|}
\hline & \multirow[t]{2}{*}{$\mathrm{n}$} & \multicolumn{2}{|c|}{ Post H1N1 NC patients } \\
\hline & & mean or $\%$ & $\mathrm{SD}$ or range \\
\hline \multicolumn{4}{|l|}{ Clinical data } \\
\hline Boys/men:girls/women, $\mathrm{n}$ & 8 & $5: 3$ & \\
\hline Age at diagnosis, years & 8 & 20.4 & $9-39$ \\
\hline \multicolumn{4}{|l|}{ Time between vaccination and } \\
\hline first symptoms, weeks & 8 & 5.25 & $2-16$ \\
\hline Weight gain* & 8 & 50 & \\
\hline \multicolumn{4}{|l|}{ NC symptoms } \\
\hline EDS at onset & 8 & 100 & \\
\hline EDS after 1 year & 8 & 100 & \\
\hline Cataplexy at onset & 8 & 100 & \\
\hline \multicolumn{4}{|l|}{ Cataplexy frequency at } \\
\hline $\begin{array}{l}\text { Onset, n/week } \\
\text { Cataplexy after } 1 \text { year }\end{array}$ & $\begin{array}{l}8 \\
8\end{array}$ & $\begin{array}{l}6.8 \\
75\end{array}$ & 3.1 \\
\hline \multicolumn{4}{|l|}{ Cataplexy frequency after } \\
\hline 1 year, n/week & 8 & 0.75 & 2.5 \\
\hline Sleep paralysis at onset & 7 & 85.7 & \\
\hline Sleep paralyis after 1 year & 7 & 28.5 & \\
\hline \multicolumn{4}{|l|}{ Hypnagogic hallucinations } \\
\hline at onset & 8 & 75 & \\
\hline \multicolumn{4}{|l|}{ Hypnagogic hallucinations } \\
\hline after 1 year & 8 & 37.5 & \\
\hline \multicolumn{4}{|l|}{ Disturbed nocturnal sleep } \\
\hline at onset & 8 & 75 & \\
\hline \multicolumn{4}{|l|}{ Disturbed nocturnal sleep } \\
\hline after 1 year & 8 & 75 & \\
\hline \multicolumn{4}{|l|}{ MLST data } \\
\hline Mean sleep latency, min & 8 & 2.00 & 1.56 \\
\hline SOREMPs (\% of naps) & 8 & 80.6 & \\
\hline \multicolumn{4}{|l|}{ Polysomnography data } \\
\hline TST, $\min$ & 7 & 413 & 47 \\
\hline Sleep efficiency & 7 & 84 & 8 \\
\hline \multicolumn{4}{|l|}{ Laboratory data } \\
\hline HLA DQB1 0602 positive & 8 & 100 & \\
\hline $\begin{array}{l}\text { CSF hypocretin }<\text { reference } \\
\text { values }\end{array}$ & 6 & 100 & \\
\hline
\end{tabular}

SOREMPs = Sleep-onset REM periods; TST = total sleep time

'Onset' is defined as within the first 6 weeks after disease onset (first symptoms).

* Weight gain is defined as an increase in weight $>5 \mathrm{~kg}$ within 3 months after disease onset.

ent purification process was detected in Pandemrix ${ }^{\circledR}$ compared to Arepanrix ${ }^{\circledR}$ [12].

In Switzerland, 2 case reports were published in detail [13] and overall 5 cases have been reported to the Swiss authorities until 2011 [14]. H1N1 vaccination coverage in Switzerland was approximately $17 \%$. Pandemrix ${ }^{\circledR}$ was used in approximately $60 \%$ of all $\mathrm{H} 1 \mathrm{~N} 1$ vaccines. It was licensed for the use in adults (18-60 years) only [15]. For children and adolescents, Focetria ${ }^{\circledR}$ and Celtura ${ }^{\circledR}$ have been licensed and used [15].

There are no statistical data available on the incidence or prevalence of sporadic NC in Switzerland. The calculated number of new cases of narcolepsy in Switzerland assuming an incidence in the literature of $0.5 / 100,000$ would be of 40 per year.

We aimed at assessing the frequency and characteristics of post-H1N1 flu vaccination narcolepsy in Switzerland.

\section{Methods}

Since patients suspected for narcolepsy are usually referred to a specialized sleep center for final diagnosis by use of MSLT, HLA typing and hypocretin analysis [16], we based our survey on the Swiss sleep centers, accredited by the Swiss Society of Sleep Research, Sleep medicine and Chronobiology (www.swiss-sleep.ch). We contacted all sleep centers for 'probable cases' of NC in context of H1N1 vaccination since 2009. In case of a positive response, centers were asked for detailed data on their cases. Data were collected and analyzed using available medical documentation of the cases. Assessment included demographic, clinical, MSLT, polysomnography (PSG) and laboratory data. Data were analyzed after anonymization.

\section{Results}

\section{Survey}

Our survey had a high response rate; 29 out of 30 (97\%) sleep centers answered. Six centers reported possible H1N1-related cases of NC: Bern University Hospital, Department of Neurology (3), University Hospital Zurich, Department of Neurology (1), University Children's Hospital Zurich, Pediatric Sleep Disorders Center (1), University Hospitals of Geneva, Sleep Laboratory (1), CENAS Sleep Center, Geneva (1), University Hospital Lausanne, Sleep Center (2). For eight out of these nine patients additional details could be obtained.

\section{Patients}

In all eight patients, EDS occurred as the first symptom, followed by cataplexy and other NC symptoms a few days or weeks later (table 1).

\section{Polysomnography}

In seven out of eight patients, PSG was performed for diagnosis. In all patients, 'sleep fragmentation,' defined by poor sleep efficiency, was reported. 


\section{Family History}

One patient reported a first-grade relative suffering from narcolepsy and 1 patient reported neurodermatitis. Besides this, no family history or co-occurrence of any other sleep or autoimmune disorders was reported.

\section{Vaccines}

In seven out of eight patients, Pandemrix ${ }^{\circledR}$ has been used. In 1 patient, Focetria ${ }^{\circledR}$ has been used.

\section{Diagnostic Latency and Date of Diagnosis}

Mean diagnostic latency was 13.4 months; six out of eight patients were diagnosed in 2010, 2 patients in 2013.

\section{Discussion}

The main aims of this study were the evaluation of the frequency and clinical characteristics of NC following H1N1 flu vaccine administration in Switzerland.

\section{Frequency}

The vaccination coverage was approximately $17 \%$ and thus comparable to other central European countries. On the basis of the calculated number of 40 newly diagnosed cases of narcolepsy per year (including post-H1N1 NC), the notified total number of (8) 9 post-H1N1 vaccination cases is within the normal range and primarily does not indicate an elevated risk. An increase of narcolepy diagnoses was mainly found in children and adolescents $[17,18]$, in Scandinavian countries in particular [19]. In Switzerland, Pandemrix ${ }^{\circledR}$ has not been applied in children and adolescents. This likely had an impact on the (probably) normal number of narcolepsy cases occurring. Additional epidemiological data, incidence data most notably, are needed for Switzerland.

\section{Clinical Characteristics}

Some recent studies have reported on specific features in post-H1N1 vaccination narcolepsy. Dauvilliers et al. [9] described an abrupt and severe onset of EDS and cataplexy and Pizza et al. [20] found higher numbers of post H1N1 NC patients with disturbed sleep. Our results are in line with these findings. In addition, we found high numbers of sleep paralysis and hallucinations immediately being present at disease onset. Our data support the description of post-H1N1 vaccination NC showing a 'full-blown' spectrum from the onset of disease.

Post-H1N1 Narcolepsy in Switzerland

\section{Clinical Course - Evolution}

There are limited data on the spontaneous course of post-H1N1 vaccination narcolepsy. Almost all of our patients $(7 / 8)$ received symptomatic pharmacological treatment. Hence, improvement of EDS, as described by a majority of the patients can be explained by the treatment. Only 3 patients were treated with specific drugs against cataplexy, but almost all patients described an improvement of this symptom in the early course. In a majority of patients, sleep fragmentation, sleep-related hallucinations and sleep paralysis also became less, later on.

A remarkable, spontaneous improvement of cataplexy has been described in sporadic NC [21], and is therefore not an exclusive feature of post H1N1 NC.

Limitations of this study include the retrospective study design, small sample size and lack of epidemiological data.

The temporal association of $\mathrm{H} 1 \mathrm{~N} 1$ flu vaccination and narcolepsy and suggested specific clinical features in post-H1N1 vaccination narcolepsy strengthen the hypothesis of an autoimmune process as a driving force in the pathogenesis of narcolepsy.

Long-term studies from countries with higher H1N1 vaccination rates are needed to better evaluate the clinical characteristics and course of post H1N1 NC.

\section{Acknowledgment}

We thank the certified sleep centers for cooperation.

\section{Disclosure Statement}

All authors declare no conflict of interest. $\mathrm{RH}$ is member of the Nightbalance advisory board.

References

Eur Neurol 2016;75:105-108 DOI: $10.1159 / 000444318$
1 Ohayon MM, Priest RG, Zulley J, Smirne S, Paiva T: Prevalence of narcolepsy symptomatology and diagnosis in the European general population. Neurology 2002;58:18261833.

2 Dauvilliers Y, Arnulf I, Mignot E: Narcolepsy with cataplexy. Lancet 2007;369:499-511.

3 Aran A, Lin L, Nevsimalova S, et al: Elevated anti-streptococcal antibodies in patients with recent narcolepsy onset. Sleep 2009;32:979983.

4 Nohynek H, Jokinen J, Partinen M, et al: AS03 adjuvanted AH1N1 vaccine associated with an abrupt increase in the incidence of childhood narcolepsy in Finland. PLoS One 2012; 7:e33536. 
5 Wijnans L, Lecomte C, de Vries C, et al: The incidence of narcolepsy in Europe: before, during, and after the influenza $\mathrm{A}(\mathrm{H} 1 \mathrm{~N} 1)$ pdm09 pandemic and vaccination campaigns. Vaccine 2013;31:1246-1254.

6 Fontana A, Gast H, Reith W, Recher M, Birchler T, Bassetti CL: Narcolepsy: autoimmunity, effector $\mathrm{T}$ cell activation due to infection, or $\mathrm{T}$ cell independent, major histocompatibility complex class II induced neuronal loss? Brain 2010;133:1300-1311.

7 Montplaisir J, Petit D, Quinn MJ, Ouakki M, Deceuninck G, Desautels A, Mignot E, De Wals P: Risk of narcolepsy associated with inactivated adjuvanted (AS03) A/H1N1 (2009) pandemic influenza vaccine in Quebec. PLoS One 2014;9:e108489.

8 Winstone AM, Stellitano L, Verity C, Andrews N, Miller E, Stowe J, Shneerson J: Clinical features of narcolepsy in children vaccinated with AS03 adjuvanted pandemic A/ H1N1 2009 influenza vaccine in England. Dev Med Child Neurol 2013;56:1117-1123.

9 Dauvilliers Y, Montplaisir J, Cochen V, et al: Post-H1N1 narcolepsy-cataplexy. Sleep 2010; 33:1428-1430.
10 Partinen M, Kornum BR, Plazzi G, Jennum P, Julkunen I, Vaarala O: Narcolepsy as an autoimmune disease: the role of H1N1 infection and vaccination. Lancet Neurol 2014;13:600613.

11 Han F, Lin L, Warby SC, et al: Narcolepsy onset is seasonal and increased following the 2009 H1N1 pandemic in China. Ann Neurol 2011;70:410-417.

12 Vaarala O, Vuorela A, Partinen M, et al: Antigenic differences between AS03 adjuvanted influenza A ( $\mathrm{H} 1 \mathrm{~N} 1)$ pandemic vaccines: implications for pandemrix-associated narcolepsy risk. PLoS One 2014;9:e114361.

13 Haba-Rubio J, Rossetti AO, Tafti M, Heinzer R: [Narcolepsy with cataplexy associated with H1N1 vaccination]. Rev Neurol (Paris) 2011; 167:563-566.

14 Mathis J, Strozzi S: Narkolepsie, eine Folge der H1N1-Grippeimpfung? Schweiz Med Forum 2012;12:8-10.

15 Swissmedic: Abschlussbericht Analyse der Datenbank PaniFlow über vermutete unerwünschte Wirkungen nach Impfungen gegen die pandemische Grippe (H1N1) 2009 in der Schweiz. Swissmedic, 2010.
16 American Academy of Sleep Medicine: International Classification of Sleep Disorders, ed 3. Darien, American Academy of Sleep Medicine, 2014.

17 Dauvilliers Y, Arnulf I, Lecendreux M, et al: Increased risk of narcolepsy in children and adults after pandemic H1N1 vaccination in France. Brain 2013;136:2486-2496.

18 Oberle D, Drechsel-Bäuerle U, Schmidtmann I, Mayer G, Keller-Stanislawski B: Incidence of narcolepsy in Germany. Sleep 2015;38: 1619-1628.

19 Partinen M, Saarenpää-Heikkilä O, Ilveskoski I, et al: Increased incidence and clinical picture of childhood narcolepsy following the 2009 H1N1 pandemic vaccination campaign in Finland. PLoS One 2012;7:e33723.

20 Pizza F, Peltola H, Sarkanen T, Moghadam KK, Plazzi G, Partinen M: Childhood narcolepsy with cataplexy: comparison between post-H1N1 vaccination and sporadic cases. Sleep Med 2014;15:262-265.

21 Pizza F, Franceschini C, Peltola H, et al: Clinical and polysomnographic course of childhood narcolepsy with cataplexy. Brain 2013; 136:3787-3795. 